\title{
IN SITU IR-ATR-SPECTROSCOPY OF ELECTRODE SURFACES
}

H. Neugebauer, A. Neckel, G. Nauer, N. Brinda-Konopik, F. Garnier ${ }^{*}$ and G. Tourillon*

Institut fur Physikalische Chemie der Universitut wien, A-1090 Wien, Wahringerstrasse 42, Austria

*aboratoire de photochimie Solaire du C.N.R.S., 2, me Henri Dunant, 94320 Thiais, France

Résumé - Dans ce papiex on prêsente une méthode rapide pour l'étude in situ des surfaces d'électrodes en contact avec un électrolyte, utilisant la spectroscopie infxa-rouge à transformêe de Fourier. On étudie les rëactions électrochimiques de substances organiques polymérisées conductrices, par spectroscopie en rêflexion totale attênuêe utilisant des éléments rëflecteurs semiconducteurs recouverts de couches minces métalliques évaporêes. On discute quelques résultats sur le processus d'oxydation de films de polymères hétêroatomiques sur des couches minces de platine.

Abstract - In this paper a fast method for in situ investigations of electrode surfaces in contact with an electrolyte using Fourier transform infrared spectroscopy is demonstrated. With attenuated total reflection spectroscopy (ATRS) using semiconducting reflection elemeats with evaporated thin metal layers the electrochemical reactions of conducting polymerized organic substances are investigated. Some results on the oxidation process of heteroaromatic polymer films on thin platinum layers are discussed.

In the last years extensive research work has been done in the field of in situ investigations of electrodes in contact with an electrolyte $/ 1 /$. A characteristic point of all proposed and applied techniques is the possibility to characterize an electrode in contact with an electrolyte at definite potentials or during controlled electrochemical experiments, e.g. cyclic voltammetry.

Most of these methods use electromagnetic waves as stimulation and detection signals, e.g. light in the uv or visible spectral range (ellipsometry, reflection spectroscopy) or infrared radiation. Spectroscopic investigations in the infrared spectral range can yield information about the molecular structure of the electrode surface and the strength of the chemical bonds of adsorbed species.

Some methods have been developed, such as EMIRS (electrochemically modulated infrared reflectance spectroscopy) /2/ and IRRAS (infrared reflectance absorption spectroscopy) /3/. Another approach to obtain the infrared spectra of an electrode surface is the attenuated total reflection spectroscopy (ATRS) / $4 /$. In this case semiconducting reflection elements, e.g. germanium, silicon or cadmium telluride, are used. The working electrode in electrochemical cella consists of one of these reflection elements covered with a thin metalic layer $/ 5 \%$. This metallic layer can be used as a substrate material for other reactions, e.g. polymexigation of organic substances. For our investigations of the oxidation reactions of polymerized heteroaromatic substances (3-methylthiophene and thiophene) we use thin piatinum layers. By means of Fourier transform infrared spectroscopy rapid changes of the surface during dynamic electrochemical experiments can be detected.

In figure 1 the typical radiation path in the spectroelectrochemical cell is demonstrated. The cell is made from teflon and is constructed as a flow cell, as de- 


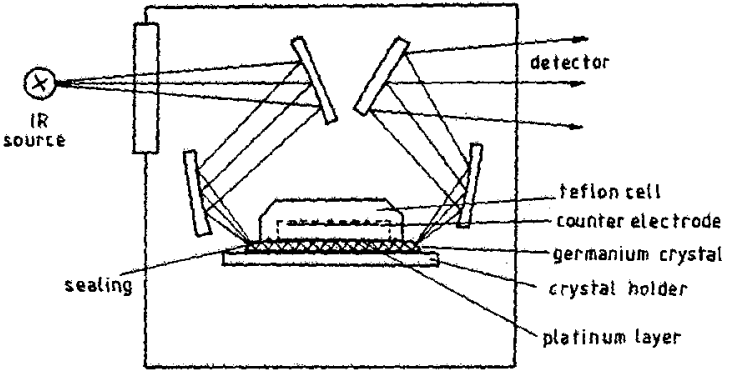

Fig. 1: Path of radiation in the spectroelectrochemical equipment.

scribed earlier $16 \%$. The counter electrode is a platinum foil, the reference electrode a saturated calomel electrode (SCE) or a silver/silvernitrate electrode in acetonitrile. After inproving the sealing of the cell it was possible to work with an evacuated spectrometer (FTIR spectrometer Bruker IFS 113V, Karlsruhe, FRG) to eliminate instabilities caused by flushing the instrument with inert ges. The electrochemical equipment consisted of a potentiostat (60TB, Jaissle, FRG), a sweep generator (PPRI, HitekInstruments, UK) and a X-Y-plotter (29000A3, Bryans, UK).

The polymerization reactions were performed in a 0.4 molar solution of 3 -methylthiophene or thiophene in acetonitrile with tetrabutylammoniumperchlorate (0.1 molar) as supporting electrolyte. The polymerization starts at anodic potentials $(+1.5 \mathrm{~V}$ againgt SCE, respectively $+1.3 \mathrm{~V}$ ageinst $\mathrm{Ag} / \mathrm{AgNO}$ in the case of thiophene) and the polymers are produced in the conducting oxidized form on the platinum layer. The oxidized forms were reduced to the non-conducting neutral forms by applying a potential of $0.0 \mathrm{~V}$ against $\mathrm{SCE}(-0.5 \mathrm{~V}$ against $\mathrm{Ag} / \mathrm{AgNO})$ on the working electrode. The obtained polymer film can be oxidized and reduced repeatediy during cyclic voltametric experiments. The potential sweep applied to the cell was 2 inv/sec, the potential limits were $0.0 \mathrm{~V}$ and $+1.0 \mathrm{~V}$ against SCE for $3-m e t h y l t h i o-$ phene, in the case of thiophene $-0.5 \mathrm{~V}$ and $+1.0 \mathrm{~V}$ against $\mathrm{Ag} / \mathrm{AgNO}_{3}$. Interferograms were measured during the oxidation and reduction half oycle. In a potential range of about 30 to $40 \mathrm{mV}$ a number of interferograms were added and stored on a disk. This ading of interferograms before performing the Fourier transformation is necessary to improve the signal/noise ratio of the spectra.

In figure $2 a$ the cyclic voltam ogram of a polythiophene layer on the platinum electrode is displayed. Figure $2 \mathrm{~b}$ shows the infrared spectra obtained during the oxidation. The reference spectrum for this plot, which is subtracted from each curve, is the spectrum of the electrolyte and was recorded before starting the polymerization. The absorption of the polymer on the platinum electrode increases very strongly during the oxidation process and is related to the change in the electrical behaviour. Furthermore some typical vibration bends occur additionally to the bands of the neutral form. The strong intensity of the bands growing during the oxidation may be explained by a vibronic intensity emhancement effect similar to the effect obtained during the doping process of polyacetylene $/ 7 /$.

In figure 3 the infraced spectra measured during the oxidation process of a poly-3methylthiophene layer on a platinum electrode is displayed. The insert shows the cyclic voltammogram of this layer. In this case the reference spectrum is the spectrum of the neutral form of the polymer in contact with the electrolyte. Corresponding to the increase of the electrical conductivity the infrared absorption of the film increases and some characteristic vibration bands occur during the oxidation process. These bands have no counterparts in the neutral form and increase with the electrochemical oxidation process. Additionally the intensities of some bands grow with different rates during the oxidation process. A band at $1100 \mathrm{~cm}^{-1}$ occurs in the high oxidation state. This band is associated with the $610_{4}^{-}$anion $/ 8 /$, and results from the intercalation of perchlorate anions into the polymer film during the oxidation process /9/. An exact interpretation of all 


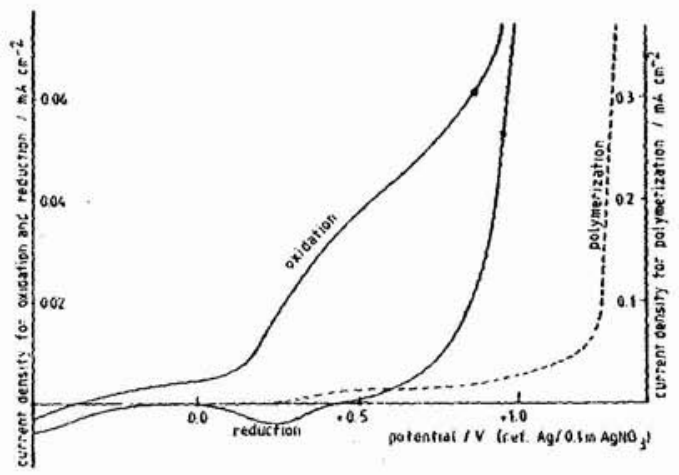

Fig. 2a: Current density/potential curves:

-..-- electrochemical polymerization of thiophene ( $\mathrm{sweep}$ rate $2 \mathrm{mV} / \mathrm{sec}$ )

oxidation and reduction of the polythiophene layer (sweep rate $2 \mathrm{mV} / \mathrm{sec}$ )
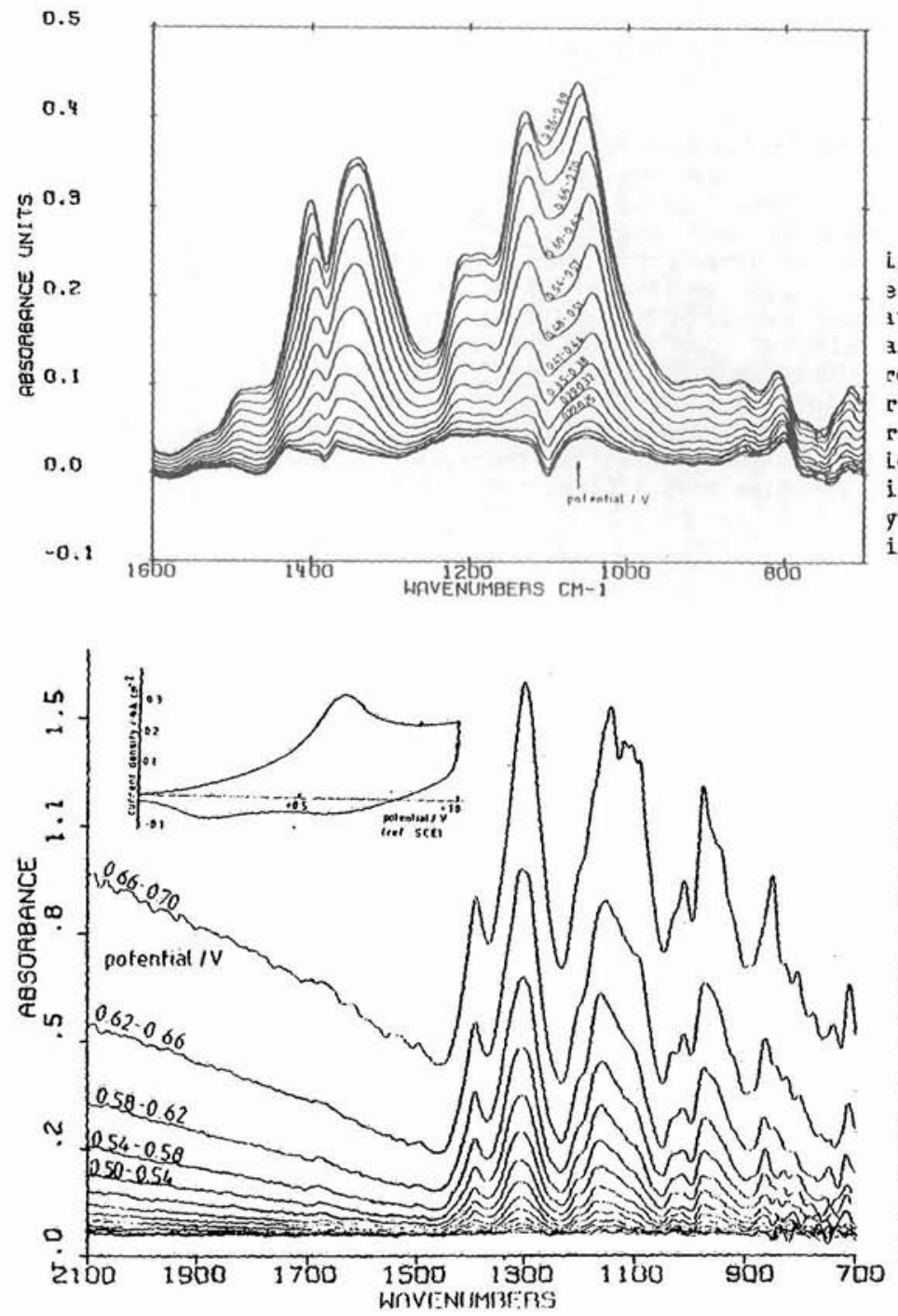

ig. $2 \mathrm{~b}$ : ATR-IR-spectra scorded during the oxiition of polythiophene. ich spectrum originates com 20 added interfero rams. Reference specrum: electrolyte soluion. The inserted potenial values refer to the yclic voltammogram in ig. $2 \mathrm{a}$.
Fig. 3: ATR-IR-spectra recorded during the oxidation of poly-3methylthiophene. Esch spectrum originates from 128 added interferograms, reference spectrum is the spectrum of the neutral form of poly-3-methylthiophene.

The insert shows the cyclic voltammogram of the oxidation and reduction of the poly-3methyl thiophene layer. 
vibration bands of the polymer and of their behaviour during the oxidation process (shift of the maxima e.g.) cannot be described at this moment, but work is carried out to get more information about the structure and the normal vibration modes of these organic conducting polymers.

The ATR spectroscopy in combination with a fast Fourier transform equipment allows to get information of an electrode surface in the infrared spectral range during dynamic electrochemical experiments and is suitable for the characterization of reaction products and the elucidation of reaction mechanisms.

Acknowledgement - We gratefully acknowledge the financial support given by the "Fonds zur Fordemang der wissenschaftichen Forschung" of Austria.

We also thank Prof. R.Kellner, Institut fir Analytische Chemie der Technischen Universitat Wien, for his kind permission to use the prith-equipment.

\section{References}

/1/ McINTYRE J.D.E*, in: Bockris J.O.M., Rand D.A.J., and Welch B.J. (eds.), Trends in Electrochemistry, Plenum Press, New York 1977

/2/ BEWICK A. and KUNIMATSU K., Surface Science 101 (1980) 131

(3) BEWICK A., KUNIMATSU K., BEDEN B., and LAMY L.C., 32 nd meeting of the International Society of Electrochemistry, Ext.Abst. vol.1, A28, p.92, Dubrovnik 1981

/4/ MARK H.B. and PONS B.S., Anal.Chem. 38 (1966) 119

15/ NEUGEBAUER H., NAUER G., BRINDA-KONOPIK N., and GIDALY G., J.Electroanal.Chem. 122 (1981) 381

16/ NEUGEBAUER H., NAUER G., BRINDA-KONOPIK N., and KELLNER R., Fresenius Z.Anal. Chem. 314 (1983) 266

/7/ RAPOLT J.F., CLARKE T.C., and SWREET G.B., J.Chem.Phys. 71 (1979) 4614

/8/ ROSS S.D., Inorganic Infrared and Raman Spectra, McGraw-Hill, Inondon 1972

19/ TOURILION G. and GARNIER F., J.Electroanal.Chem. 135 (1982) 173 